\title{
Sistem Kendali PID pada Pengendalian Suhu untuk Kestabilan Proses Pemanasan Minuman Sari Jagung
}

\author{
${ }^{1}$ Bambang Sampurno*), ${ }^{2}$ Arief Abdurrakhman \& 2 Herry Sufyan Hadi \\ 1 Jurusan Teknik Mesin, Institut Teknologi Sepuluh Nopember, Surabaya \\ 2Jurusan Teknik Fisika, Institut Teknologi Sepuluh Nopember, Surabaya \\ bsampurno1965@gmail.com*), 2ariefabdurrakhman@gmail.com, 2sh_herry@yahoo.co.id
}

\begin{abstract}
Abstrak
Permasalahan utama dari proses pembuatan minuman sari jagung yang ada di UD Samara Mart Surabaya adalah tidak tepatnya suhu dan lamapemanasan yang diinginkan. Pada proses perebusan biji jagung (pemanasan pertama) seharusnya suhu uap air didalam tangki dipertahankan $110{ }^{\circ} \mathrm{C}$ selama 2 (dua) jam, sedangkan pada proses perebusan sari jagung (pemanasan kedua) seharusnya suhu uap air dipertahankan $100{ }^{\circ} \mathrm{C}$ dengan waktu 1 jam. Kondisi ini seringkali tidak terjadi karena proses pengamatan dan pengaturan suhu dilakukan secara manual. Pada gilirannya produktifitas minuman sari jagung UD Samara Mart masih rendah (130 botol/hari). Oleh karena itu diperlukan sistem otomasi pada proses pemanasan sari jagung agar mampu memperoleh suhu yang diinginkan dalam jangka waktu yang tepat.Penelitian diawali dengan pemodelan perpindahan panas yang terjadi pada proses pemanasan, dimana model tersebut menjadi acuan dalam melakukan simulasi. Simulasi komputer dilakukan dengan memvariasikan aliran panas pada tanki untuk mode kontroler yang tepat dengan indikator respon temperatur. Berdasarkan hasil simulasi diperoleh besarnya $K_{p}=3,199, K_{i}=1,4296$, dan $K_{d}=0,0019$, dimana besarnya panas yang dibutuhkan rata-rata sebesar $3.768,25$ Wuntuk pemanasan pertama, dan sebesar 3.748,41 W untuk pemanasan kedua. Sedangkan besarnya rise time selama 850 detik, overshoot sebesar $7,33 \%$ dan settling timenya sebesar 2000 detik. Sedangkan secara eksperimen menunjukkan besarnya rise time 853 detik overshoot $8 \%$, settling time 2000 detik.
\end{abstract}

Kata kunci: minuman sari jagung, rasa, pemanasan, otomasi dan suhu

\section{Pendahuluan}

Saat ini telah banyak proses pembuatan minuman siap saji yang bahan bakunya dari tanaman, seperti sari kedelai, sari kunyit, sari jahe, sari tebu, sari jagung, sari lidah buaya, dan lain sebagainya. Beberapa minuman tersebut merupakan jenis pangan atau produk pangan yang memiliki ciri-ciri fungsional sehingga berperan dalam perlindungan atau pencegahan, pengobatan terhadap penyakit, peningkatan kinerja fungsi tubuh optimal, dan memperlambat proses penuaan (Sampoerno, et al.) [1]. Menurut Goldberg [2], dasar pertimbangan konsumen di negara-negara maju dalam memilih bahan pangan bukan hanya bertumpu pada kandungan gizi serta kelezatannya, tetapi juga pengaruhnya terhadap kesehatan tubuh. Fenomena tersebut melahirkan konsep pangan fungsional. Beberapa fungsi tersebut menjadikan minuman dari sari tanaman banyak diminati oleh sebagian besar masyarakat, khususnya di Indonesia, sehingga permintaan terhadap produk ini cenderung meningkat. Namun permintaan yang meningkat tersebut masih belum diiringi dengan peningkatan kualitas proses produksi yang masih konvensional, sehingga menyebabkan rantai pasokan minuman dari sari tanaman ini terganggu karena laju produksi yang cenderung konstan.

Salah satu proses produksi yang masih bersifat konvensional adalah produksi minuman siap saji dari sari jagung. Adapun studi kasus dalam penelitian ini adalah produsen minuman sari jagung di Surabaya dengan kapasitas produksi yang dicapai saat ini adalah 130 botol/hari. Pada sisi yang lain, permintaan saat ini sudah mencapai diatas 500 botol/hari. Sehingga laju produksi sudah tidak mampu lagi memenuhi permintaan konsumen, sehingga diperlakukan upaya optimasi pada proses produksi minuman sari jagung pada produsen ini.

Proses pembuatan produk minuman sari jagung diawali dengan mengupas klobot jagung secara manual, kemudian proses kedua yaitu pemipilan jagung dengan menggunakan pisau potong. Selanjutnya proses yang ketiga,biji jagung yang sudah dipipil kemudian direbus di tangki (dandang) dengan menggunakan uap air yang dipanaskan (dikukus) dimana sumber panas yang digunakan adalah kompor gas high pressure sebagaimana gambar 1.3. Berdasarkan pengalaman pekerja pada bagian proses produksi, untuk kapasitas $12 \mathrm{~kg}$ jagung pipilan pada tangki yang berukuran diameter $50 \mathrm{~cm}$ dan tinggi $30 \mathrm{~cm}$ dibutuhkan uap air yang memiliki suhu $110^{\circ} \mathrm{C}$ dalam waktu 2 jam. Namun ketepatan suhu dan lama pemanasan seringkali tidak terjadi karena tidak ada indikator temperatur pada tangki dan tidak dilakukan pengaturan tekanan LPG pada kompor high pressure agar panas yang diberikan stabil.

Proses yang keempat adalah penggilingan jagung yang sudah direbus, dan proses yang kelima adalah pencampuran hasil gilingan jagung dengan air, gula dan daun pandan untuk memperoleh minuman yang bernuansa jagung dengan tingkat kemanisan yang optimal dilengkapi aroma pandan. 
Pada 5 proses tersebut, salah satu proses yang dapat dilakukan optimasi adalah proses yang ketiga, yaitu pemanasan. Fase ini merupakan proses utama yang menentukan kualitas minuman sari jagung. Sehingga diperlukan alat otomasi pada proses pemanasan di tangki agar suhu dan lama pemanasan sesuai dengan kebutuhan proses.

Adapun beberapa penelitian tentang sistem kontrol temperatur pernah dilakukan oleh Setiawan A, et al [3]. Penelitian yang dilakukan adalah mendisain alat alat sistem kontrol suhu dan kelembaban untuk optimasi proses pembuatan tempe pada skala industri rumah tangga. Desain alat ini terdiri dari rangkaian power supply, rangkaian sensor,dan minimum system dari mikrokontroler ATmega16. Power supply berfungsi untuk memberikan tegangan yang dibutuhkan pada masing-masing rangkaian tersebut. Mikrokontroler ATmega16 sebagai pusat pengaturan pada rangkaian sensor, dan rangkaian aktuator. Sistem kontrol yang digunakan pada desain ini adalah on-off. sistem kontrol ini diaplikasikan pada proses optimasi pembuatan tempe sebagai pengendali suhu dan kelembaban dengan kondisi awal yang sudah di setting nilai suhu dan kelembaban pada programnya. Mikrokontroler ini juga bertindak sebagai eksekutor untuk menggearakkan aktuator. Pengendalian temperatur yang lain juga pernah dilakukan oleh Bayusari I, et.al [4]. Penelitian ini ini membahas tentang perancangan sistem pemantauan pengendali suhu pada sistem stirred tank heater yang mempunyai peranan penting dalam proses industri. Pemantauan sistem kendali suhu pada stirred tank heater ini dirancang menggunakan Supervisory Control and Data Acquisition (SCADA) yang berfungsi memantau jalannya sistem. Sedangkan aktuator yang akan dikendalikan adalah posisi bukaan burner sehingga besarnya panas akan dapat diatur guna memenuhi set-point yang telah ditentukan. Pengendali suhu yang juga digunakan sebagai Remote Terminal Unit (RTU) adalah Programmable Logic Controller (PLC). Hasil pengujian yang tertera pada tampilan sistem SCADA diperoleh bahwa persentase error rata-rata untuk data pengujian set-point adalah $0.76687 \%$ serta persentase error untuk data suhu adalah $0.082 \%$.

Berdasarkan pada beberapa kajian diatas, maka pada penelitian ini dibuat sistem pemanasan larutan sari jagung dengan menggunakan komponen utama yang digunakan untuk menjaga kondisi tersebut berupa sensor suhu sebagai indikator sekaligus elemen umpan balik, kontroler PID sebagai pembanding sekaligus penentual sinyal kontrol pengatur elemen pengendali serta aktuator berupa control valve sebagai elemen pengendali tekanan kompor gas untuk mengatur variasi panas yang diberikan kapada tangki.

\section{Diskusi}

Adapun teori yang akan dibahas pada tulisan ini yaitu tori tentang perpindahan panas secara konduksi, konveksi dan kontrol PID.

\subsection{Teori Perpindahan Panas}

Konduksi satu dimensi pada dinding datar, distribusi temperatur hanya kearah satu sumbu saja misalnya sumbu $x$, sehingga perpindahan panas hanya terjadi kearah sumbu $x$ saja.

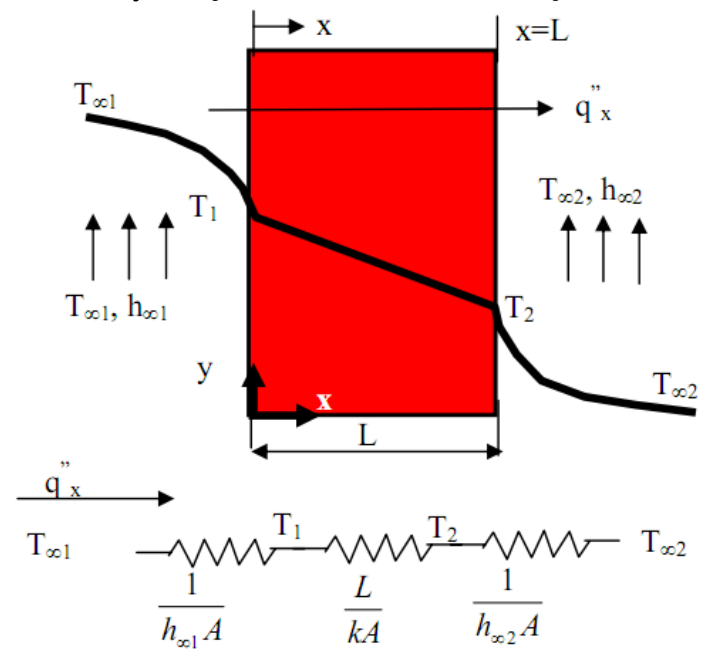

Gambar 1 Perpindahan panas pada dinding datar

Pada gambar diatas terlihat panas berpindah secara konveksi dari udara di bagian dalam ke dinding dalam, kemudian dilanjutkan dengan konduksi dari dinding dalam ke dinding luar, lalu diteruskan lagi dengan konveksi dari dinding luar ke udara luar.

Konduksi satu dimensi ke arah sumbu X saja (Gambar 2):

$$
\begin{aligned}
& q_{x}=-k A \frac{d T}{d x} \\
& q_{x} \int_{x_{1}}^{x_{2}} d x=-k A \int_{T_{1}}^{T_{2}} d T \\
& q_{x}=-\frac{k A}{L}\left(T_{2}-T_{1}\right)
\end{aligned}
$$

Dimana: $q_{x}=$ besarnya perpindahan kalor secara konduksi(W)

$K=$ koefisien konduksi $(\mathrm{W} / \mathrm{m} . \mathrm{K})$

$A=$ Luas Penampang $\left(\mathrm{m}^{2}\right)$

$L \quad=$ Panjang dinding datar $(\mathrm{m})$

$T_{1}=$ Temperatur $1(\mathrm{~K})$

$T_{2}=$ Temperatur $2(\mathrm{~K})$ 
Pada kasus ini, pemanasan pertama (pemasakan) sari jagung kormil di dalam dandang dikondisikan selalu dalam temperatur yg konstan $\mathrm{T}_{\infty 1}=110^{\circ} \mathrm{C}$ selama 2 jam dan pemanasan kedua sebesar $T_{\infty} 2$ $=100^{\circ} \mathrm{C}$ selama 1 jam. Untuk kasus perpindahan kalor pada dandang ini diasumsikan sama dengan Gambar 2. Sehingga perpindahan panas seperti tersebut diatas peristiwa difusi panas dianalogikan dengan aliran arus listrik dan hambatan listrik dianalogikan dengan hambatan perpindahan panas, serta beda potensial dianalogikan dengan beda temperatur.

$R_{\text {kond }}=\frac{\Delta T}{q}=\frac{L}{K}$

Sebaliknya laju perpindahan panas dapat ditulis:

$q_{\text {kond }}=\frac{\Delta T}{R_{\text {kond }}}=\frac{\left(T_{2}-T_{1}\right)}{R_{\text {kond }}}$

$R_{\text {kond }}$ disebut hambatan perpindahan panas konduksi. Analisis yang sama jika diterapkan pada kasus konveksi, maka didapat hambatan perpindahan panas konveksi $R_{\text {konv }}$ :

$q=h A\left(T_{s}-T_{\infty}\right)$

$R_{\text {konv }}=\frac{\Delta T}{q}=\frac{1}{h A}$

Dimana: $h=$ koefisien konveksi $\left(\mathrm{W} / \mathrm{m}^{2} . \mathrm{K}\right)$

Dan laju perpindahan panas konveksi ditulis:

$q_{\text {konv }}=\frac{\Delta T}{R_{\text {konv }}}=\frac{\left(T_{2}-T_{1}\right)}{R_{k o n v}}$

Dalam suatu rangkaian hambatan listrik arus yang mengalir di tiap-tiap hambatan sama, dan analoginya laju perpindahan panas pada tiap-tiap hambatan perpindahan panas juga sama, maka:

$q_{x}=\frac{\left(T_{\infty 1}-T_{1}\right)}{\frac{1}{h_{\infty 1}}}=\frac{\left(T_{2}-T_{1}\right)}{\frac{L}{K A}}=\frac{\left(T_{2}-T_{\infty 2}\right)}{\frac{1}{h_{\infty 1}}}$

Dan juga dapat ditulis dalam bentuk beda temperatur total:

$q_{x}=\frac{\left(T_{\infty 1}-T_{\infty 2}\right)}{R_{t o t}}=\frac{\Delta T}{R_{t o t}}$

$R_{\text {tot }}=\frac{1}{h_{\infty 1} A}+\frac{L}{K A}+\frac{1}{h_{\infty 2} A}$

$R_{\text {tot }}$ disebut hambatan perpindahan panas keseluruhan (overall heat transfer resistant).

Persamaan (9) dapat ditulis dalam bentuk lain yaitu:

$q_{x}=U A \Delta T$
$U A=\frac{1}{R_{t o t}}=\frac{1}{\frac{1}{h_{\infty 1} A}+\frac{L}{K A}+\frac{1}{h_{\infty 2} A}}$

$U=\frac{1}{\frac{1}{h_{\infty 1} A}+\frac{L}{K A}+\frac{1}{h_{\infty 2} A}}$

$U$ disebut koefisien perpindahan panas keseluruhan

\subsection{Teori Kontrol}

Ada beberapa macam sistem kendali yang bisa kita gunakan untuk mengontrol beberapa sistem yang kita inginkan. Berikut akan dijelaskan beberapa macam sistem kendali yang biasa digunakan.

\subsubsection{Kendali PID}

Sistem kendali PID merupakan sistem kendali loop tertutup yang cukup sederhana dan memiliki performa yang bagus. Namun kendali ini tidak dapat bekerja dengan baik apabila terjadi ketidakpastian dan ketidaklinieran pada sistem.

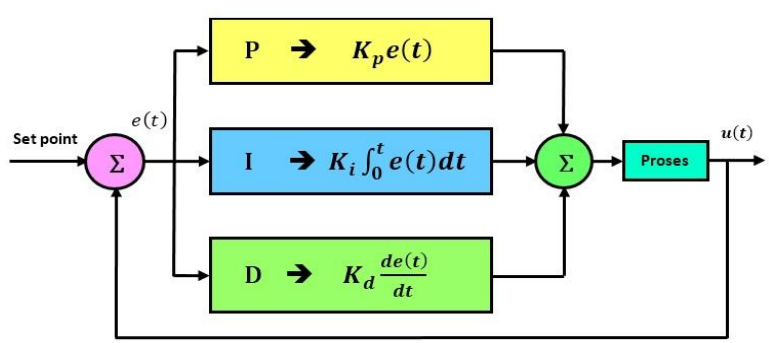

Gambar 2. Diagram blok sistem kendali PID

Sistem kendali PID terdiri dari tiga macam kendali, yaitu kendali P (Proportional), D (Derivatif) dan I (Integral), dengan masing-masing memiliki kelebihan dan kekurangan. Tujuan penggabungan ketiga jenis kendali tersebut adalah untuk menutupi kekurangan dan menonjolkan kelebihan dari masing-masing jenis kendali.Dalam perancangan sistem kendali PID yang perlu dilakukan adalah mengatur parameter $\mathrm{K}_{\mathrm{P}}, \mathrm{K}_{\mathrm{I}}$, dan $K_{D}$ agar respon sinyal keluaran sistem terhadap masukan memiliki harga tertentu sebagaimana yang diiginkan.Dalam penelitian ini PID controller akan didesain dengan menggunakan metode tuning Ziegler - Nichols.

\subsubsection{Tuning PID}

Permasalahan terbesar dalam desain kontroler PID adalah menentukan nilai $\mathrm{Kp}$, $\mathrm{Ki}$ dan $\mathrm{Kd}$. Metode-metode tuning dilakukan berdasarkan metode matematika system/plant. Jika model matematika tidak diketahui maka dilakukan dengan eksperimen terhadap sistem.Cara 
menentukan tuning PID juga bisa berdasarkan metode tuning Ziegler-Nichols. Metode ini bertujuan untuk pencapaian maximum overshoot (MO): $25 \%$ terhadap masukan step.

\subsubsection{Metode Pertama Ziegler- Nichols}

Metode pertama diterapkan pada plant dengan step respons dari bentuk yang ditunjukkan dalam Gambar 6, jenis respon ini adalah khusus berlaku untuk sistem orde pertama dengan transpotasi delay. Jika sistem tidak mencakup integrator ataupun nilai-nilai kutup pasangan komplek yang dominan, maka kurva respon sebuah tangga satuan kelihatan seperti kurva berbentuk - S, (jika respon tidak memiliki kurva berbentuk - $\mathrm{S}$, maka metode ini tidak berlaku).Kurva-kurva respon tangga sedemikian dapat dihasilkan secara ekperimen atau dari simulasi dinamik sistem.
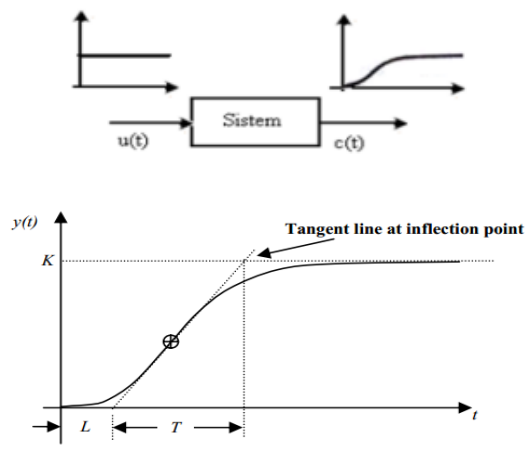

Gambar 3. Kurva respon untuk metode Ziegler - Nichols orde pertama

Karakteristik respon diberikan oleh dua parameter, $\mathrm{L}$ adalah sebagai time delay dan $\mathrm{T}$ merupakan Time constant. Ini didapatkan dengan mengambarkan garis singgung pada titik perubahan kurva berbentuk $S$ dan menentukan perpotongan garis singgung dengan sumbu waktu dan garis $\mathrm{c}(\mathrm{t})=\mathrm{K}$, seperti diperlihatkan pada Gambar 3. C(s)/u(s) dapat didekati dengan sistem orde pertama dengan keterlambatan transport.

$\frac{C(s)}{U(s)}=\frac{K_{e}^{-L s}}{T s+1}$

Ziegler - Nichols menyarankan pengaturan nilai $\mathrm{Kp}$, Ti dan $\mathrm{Td}$ berdasarkan rumus yang diberikan dalam Tabel 1.

Tabel 1 Aturan peyepadanan Ziegler - Nichols orde pertama.

\begin{tabular}{|c|c|c|c|}
\hline PID Type & $\boldsymbol{K}_{p}$ & $\boldsymbol{T}_{i}=\boldsymbol{K}_{p} / \boldsymbol{K}_{i}$ & $\boldsymbol{T}_{d}=\boldsymbol{K}_{d} / \boldsymbol{K}_{p}$ \\
\hline P & $\frac{T}{L}$ & $\infty$ & 0 \\
\hline PI & $0.9 \frac{T}{L}$ & $\frac{L}{0.3}$ & 0 \\
\hline PID & $1.2 \frac{T}{L}$ & $2 L$ & $0.5 L$ \\
\hline
\end{tabular}

2.2.2.2 Metode kedua
Dalam metode kedua, mula-mula kita mengatur $T_{i}=\propto$ dan $T_{d}=0$. Dengan menggunakan tindakan kontrol proporsional (Gambar 4a), menambahkan $\mathrm{K}_{\mathrm{p}}$ dari $\mathrm{O}$ kesuatu nilai kritis $\mathrm{K}_{\mathrm{cr}}$, disini mula-mula keluaran memiliki osilasi yang berkesinambungan (jika kelauran tidak memiliki osilasi yang berkesinambungan untuk nilai $K_{p}$ ) maka metode ini tidak berlaku. Jadi penguatan kritis $\mathrm{K}_{\mathrm{cr}}$ periode kritis $\mathrm{P}_{\mathrm{cr}}$ yang sesuai ditentukan secara ekperimen (Gambar 7b).

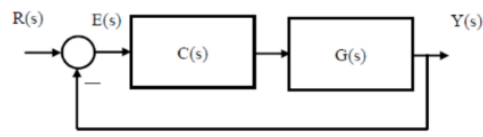

(a)

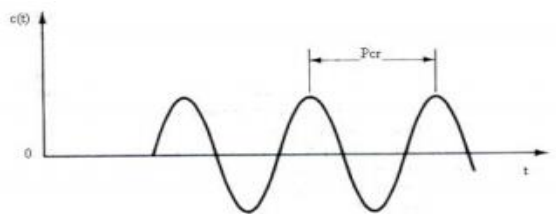

(b)

Gambar 4. (a) Sistem loop tertutup dengan alat kontrol proporsional, (b) Osilasi berkesinambungan dari periode $P$ cr.

Ziegler - Nichols menyarankan pengaturan parameter $K_{p}, T_{i}$, dan $T_{d}$ berdasarkan rumusan yang diperlihatkan pada Tabel 2.Berdasarkan tabel 2.3 nilai $K_{p}, K_{d}$, dan $K_{\text {I }}$ dapat ditentukan dan nilai dari $P_{c r}$ bisa ditentukan dengan persamaan:

$$
P_{c r}=2 \pi / \omega
$$

Dimana $\omega$ adalah frekwensi osilasi yang didapatkan dari persamaan Routh-Hurwitz stability criteria.

Tabel 2 Aturan Pengaturan Ziegler-Nichols orde 2.

\begin{tabular}{|c|c|c|c|}
\hline PID Type & $\boldsymbol{K}_{\boldsymbol{p}}$ & $\boldsymbol{T}_{\boldsymbol{i}}$ & $\boldsymbol{T}_{\boldsymbol{d}}$ \\
\hline $\mathrm{P}$ & $0.5 K_{c r}$ & $\infty$ & 0 \\
\hline PI & $0.45 K_{c r}$ & $\frac{P_{c r}}{1.2}$ & 0 \\
\hline PID & $0.6 K_{c r}$ & $\frac{P_{c r}}{2}$ & $\frac{P_{c r}}{8}$ \\
\hline
\end{tabular}

\subsection{Metodologi Penelitian}

Pada bagian ini akan dibahas lebih jauh tentang serangkaian peralatan yang digunakan pada penelitian. Metode yang digunakan adalah dua, yaitu pengendalian suhu secara simulasi menggunakan software Matlab-Simulink dan Metode menggunakan serangkain Eksperiment untuk mendapatkan hasil yang nyata untuk penyelesaian dari permasalahan pada bagian pendahuluan.

\subsubsection{Metode Simulasi}


Adapun langkah-langkah kerja yang dilakukan adalah sebagai berikut:

1. Memodelkan sistem perpindahan panas pada tangki.

2. Menentukan perpindahan panas yang terjadi pada tangki

3. Membuat model matematis dari perpindahan panas yang terjadi

4. Menetukan besarnya parameter dari model.

5. Menambahkan kontroller PID

6. Menentukan besarnya nilai $K_{p}, K_{i}$, dan $K_{d}$

7. Membahas hasil yang didapatkan dari simulasi

\subsubsection{Metode Eksperimen}

Tujuan dari eksperiment ini adalah untuk mendapatkan kotroller yang sesuai untuk mengendalikan besarnya suhu pemanasan. Adapun hasil Assembly peralatan dapat dilihat pada Gambar 5.

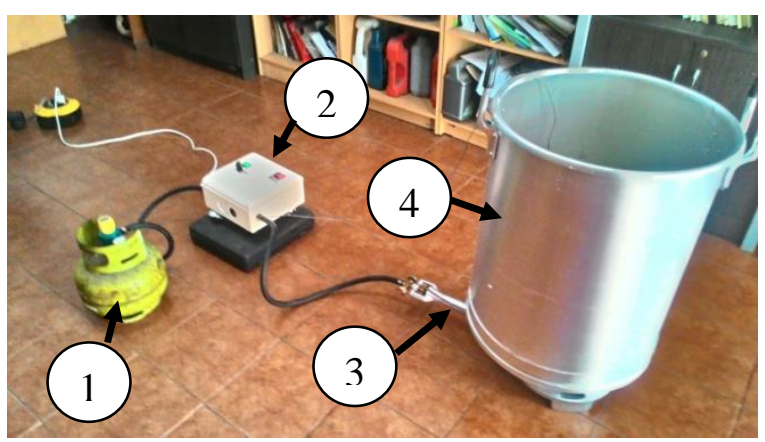

Gambar 5. Serangkaian assembly Eksperimen

Keterangan Gambar:

1. Elpiji sebagai bahan bakar

2. Kontroller

3. Kompor gas high pressure

4. Tangki/ dandang

Gambar 5. merupakan hasil perncangan dari eksperimen. Peralatan yang digunakan adalah sebuah gas elpiji melon (3kg), kontroller PID, dan seubah tangki pemanas untuk memanaskan minuman sari jagung. Adapun sistem kontroller kontroller yang digunakan untuk mengendalikan besarnya suhu supaya konstan adalah sebagai berikut:

1. Sensor suhu (Thermocouple) digunakan sebagai alat untuk mengetahui besarnya suhu dari minuman.

2. Selenoid berfungsi untuk memutuskan atau menyalurkan aliran gas elpiji.

3. Ketika suhu masih belum tercapai, maka aliran elpiji akan besar dan nyala api besar.

4. Ketika suhu tercapai sesuai dengan yang diset, maka aliran elpiji akan direduksi oleh solenoid dan nyala api kompor menjadi kecil.

5. Ketika nyala api kecil, suhu otomatis akan turun, dan kompor akan menyala lagi untuk menjaga agar suhu dari pemanasan bisa terkendali.

\subsection{Hasil dan Pembahasan}

\subsubsection{Hasil Perhitungan dan Simulasi}

Pada bagian ini akan dibahas tentang hasil simulasi pengendalian temperature menggunakan kontroller PID. Sebelum membahas lebih jauh tentang pengendalian temperature menggunakan PID, akan dibahas tentang perpindahan panas yang ada pada dandang. Pada bagian ini digunakan persamaan perpindahan panas untuk mendapatkan besarnya perpindahan panas yang terjadi pada tangki [7].
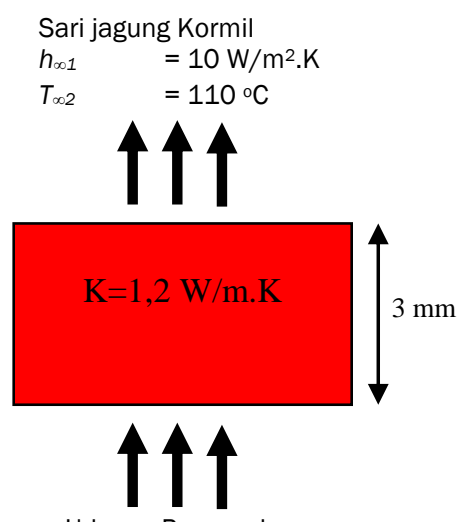

Udara Panas kompor high Pressure $h_{\infty I}=25 \mathrm{~W} / \mathrm{m}^{2} . \mathrm{K}$ $T_{\infty I}=2000^{\circ} \mathrm{C}$

$U=\frac{1}{\frac{1}{h_{\infty 1}}+\frac{L}{K}+\frac{1}{h_{\infty 2}}}=\frac{1}{\frac{1}{25}+\frac{0,003}{1,2}+\frac{1}{10}}=7,018 \mathrm{~W} / \mathrm{m}^{2} \mathrm{~K}$

$A=\pi \cdot r^{2}=3,14 \times 0,3^{2}=0,2826 \mathrm{~m}^{2}$

$q=U \cdot A \cdot\left(T_{\infty 1}-T_{\infty 2}\right)$

Sehingga besarnya perpindahan panas yang terjadi:

$q_{1}=7,018 \mathrm{~W} / \mathrm{m}^{2} \mathrm{~K} \cdot 0,2826 \mathrm{~m}^{2} \cdot(2273-373) \mathrm{K}$

$=3.768,25 \mathrm{~W}$

dan besarnya pemanasan kedua:

$q_{2}=7,018 \mathrm{~W} / \mathrm{m}^{2} \mathrm{~K} .0,2826 \mathrm{~m}^{2} \cdot(2273-383) \mathrm{K}$

$=3.748,41 \mathrm{~W}$

Dengan input berupa bukaan selang elpiji (massa gas yang terbakar), maka diperoleh data massa jenis $\left(\rho=536 \frac{\mathrm{kg}}{\mathrm{m}^{3}}\right)$, rapat jenis $(R)=49,6 \mathrm{MJ} / \mathrm{kg}$, dan diameter tangki pemanas $(d)=$ $50 \mathrm{~cm}$, kontrol valve $=\frac{1}{0,2 \mathrm{~s}+1}$, Transmitter $=$ $\frac{1}{0,05 s+1}$, maka diperoleh: 


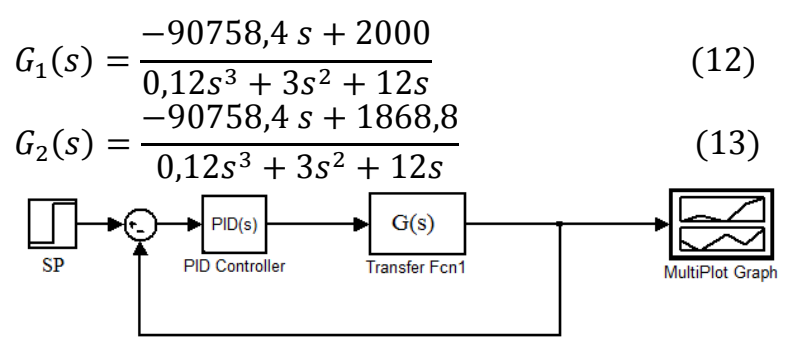

Gambar 11. Blok diagram suhu pemanasan kedua dengan PID controller

Gambar 11 merupakan blok diagram MatlabSimulink dengan kontroller PID dimana nilai $K_{p}=3,199, K_{i}=1,4296$, dan $K_{d}=0,0019$. Nilai ini diperoleh dengan cara auto tuning untuk memudahkan dalam mendapatkan nilainya.

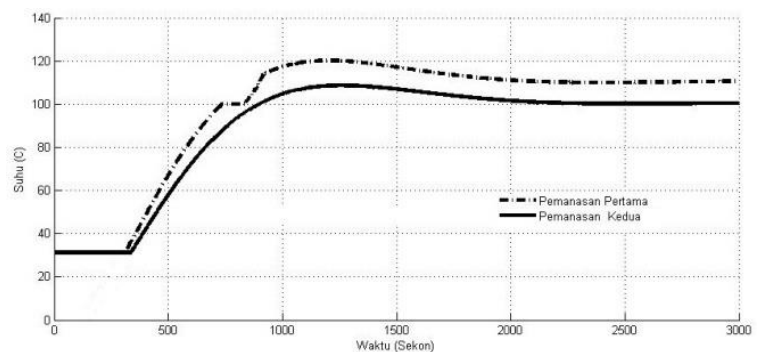

Gambar 12. Respon suhu pemanasan kedua dengan PID controller

Berdasarkan Gambar 12 dapat diketahui keluaran sistem untuk mencapai setpoint memiliki error sistem nol, ini berarti nilai actual dengan nilai yang di inginkan dapat dicapai tanpa adanya penyimpangan. Pada pemanasan pertama dan kedua diperoleh nilai yang sama bahwa besarnya rise time sebesar 850 detik, over shoot sebesar $7,33 \%$ dan settling time yang dicapai sistem adalah 2000 detik. Namun ada perbedaan akibat viskositas fluida yang berbeda. Pada pemanasan pertama terlihat bahwa suhu cenderung konstan pada suhu $100^{\circ} \mathrm{C}$. Hal ini terjadi karena pada pada keadaan ini, air mengalai perubahan fase dari cair menjadi gas. Berbeda halnya dengan pemanasan ke dua karena pada pemanasan kedua, fluida yang dipanaskan berupa campuran antara air dan sari jagung.

\subsubsection{Hasil Eksperimen}

Analisa hasil eksperimen dilakukan pada dua kali pemanasan yaitu pemanasan pertama dan pemanasan ke dua. Adapun pengambilan data diperoleh dengan cara mencatat besarnya perubahan suhu berdasarkan variasi waktu. Setelah itu, hasil dari pengambilan data ini di gambarkan dalam bentuk grafik seperti terlihat pada Gambar 13.

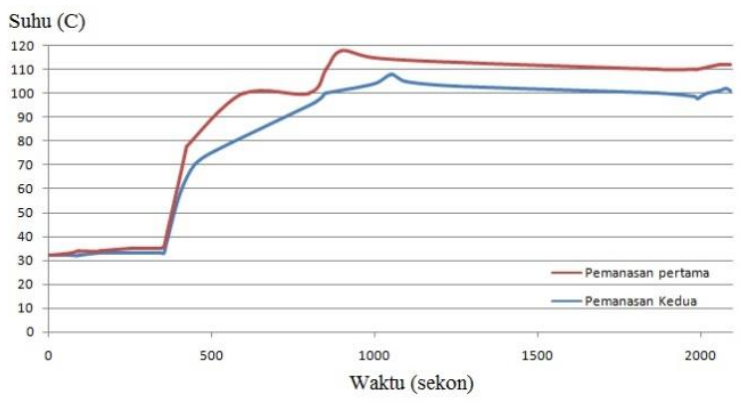

Gambar 13. Hasil Pengendalian suhu secara eksperimen

Dari Gambar 13 terlihat bahwa besarnya rise time sebesar 853 sekon, settling time sebesar 2000 sekon, overshoot sebesar $8 \%$ dan. Dari gambar 13 juga terlihat bahwa besarnya fluktuasi berbeda. Hal ini terjadi karena pada pemanasan pertama, fluida yang dipakai adalah air murni yang dipanaskan hingga pada suhu $110^{\circ} \mathrm{C}$. sedangkan pada pemanasan kedua, fluida yang dipanaskan berupa campuran antara air dan sari jagung sehingga besarnya viskositasnya menjadi lebih besar.

\section{Kesimpulan}

Adapun kesimpulan dari makalah ini adalah sebagai berikut:

1. Hasil simulasi menunjukkan bahwa Pada pemanasan pertama dan kedua diperoleh nilai yang sama bahwa besarnya rise time sebesar 850 detik, over shoot sebesar 7,33\% dan settling time yang dicapai sistem adalah 2000 detik.

2. Hasil eksperimen menunjukkan bahwa besarnya rise time sebesar 853 sekon, settling time sebesar 2000 sekon, overshoot sebesar $8 \%$.

3. Pada pemanasan pertama suhu cenderung konstan pada saat mencapai $100^{\circ} \mathrm{C}$, sedangkan pada pemanasan ke dua, suhu terus naik sampai suhu yang diinginkan bisa tercapai. Hal ini karena viskositas fluida pada pemanasan pertama dan kedua berbeda.

\section{Ucapan Terima kasih}

Terima kasih kami sampaikan kepada Kemenristekdikti melalui Institut Teknologi Sepuluh Nopember memberikan dana BOPTN dengan skema pengabdian kepada masyarakat telah membiayai kegiatan ini. Demikian pula disampaikan terima kasih kepada Kepala Laboratorium Mekatronika Diploma Teknik Mesin ITS yang telah memberikan fasilitas untuk menyelesaikan kegiatan pengabdian kepada masyarakat ini. 


\section{Daftar Pustaka}

[1] Sampoerna dan D. fardiaz. 2001. “Kebijakan dan Pengembangan pangan Fungsional dan Suplemen di Indonesia. Pangan Tradisional Basis Bagi Industri Pangan Fungsional dan Suplemen. Pusat Kajian Makanan Tradisional, Institut Pertanian Bogor, Bogor. Hal. 1-15

[2] Goldberg I. 1994. “Functional Foods, Designer Foods, Pharmafoods,Nutraceuticals. Chapman and Hall, London.

[3] Setiawan A, Adil R, Sulistijono G. 2013. "Desain Alat Sistem Kontrol Suhu Dan Kelembaban Untuk Optimasi Proses Pembuatan Tempe Pada Skala Industri Rumah Tangga". Politeknik Elektro Negeri Surabaya. Surabaya.

[4] Bayusari I, Caroline, Septiadi R, Suprapto B. Y. 2011. "Perancangan Sistem Pemantauan Pengendali Suhu pada Stirred Tank Heater menggunakan Supervisory Control and Data Acquisition (SCADA)". Jurusan Teknik Elektro. Fakultas Teknik. Universitas Sriwijaya. Palembang.

[5] Johnson Curtis D 2003. "Process Control Instrumentation Technology", Prentice Hall New Jersy USA.

[6] Raven F. A, 1995,"Automatic Control Engineering", McGraw-Hill Inc. New York.

[7] Incropera FP, Dewitt DP, Bergman TL, Lavine AS, 2011, “Fundamental of Heat and Mas Transfer, \& $7^{\text {th }}$ edition, John Wiley and Son, United States of America. 